G. C. Wittstein, Analyse d. Asche d. Euphorbia anygdalö̈dos etc. 341

suchung von Hager \& Jacobsen ein schwach weingeistiger, mit Zucker zum Syrup gemachter Auszug der Pomeranzenschalen ist. Der Unterschied zwischen beiden Präparaten ist so gering, dass sie sowohl, wie die Namen Laroche und Laroze für identisch angesehen werden können.

\title{
Analyse der Asche der Euphorbia amygdaloïdes und der Herniaria glabra von verschiedenen Standorten.
}

Von G. C. Wittstein.

Es wurden die ganzen Pflanzen im blühenden Zustande zur Untersuchung verwendet.

1) Euphorbia amygdaloides.

a.
Von Kiesel-
boden. $\begin{gathered}\begin{array}{c}\text { Von einem } \\ \text { anderen Kie- } \\ \text { selboden. }\end{array}\end{gathered}$

Ausbeute der lufttrocknen Pflanzen

an Asche

5,936 Proc. 4,850 Proc.

Procentische Zusammensetzung der Aschen.

Kali

Natron

Natrium (mit dem Chlor verbunden)

Kalk

Magnesia

Alaunerde

Eisenoxyd

Manganoxyduloxyd

Chlor

Schwefelsäure

Phosphorsäure

Kieselsäure

Kohlensäure
33,441 Proc. 15,362 Proc.

$1,443 " 0,298$,

$1,155,0,540$,

$15,121 ” 33,135$ ”

4,370 " 4,796 "

$1,057,1,325$ ”

0,413 " 0,656 ,

$0,344 "$ Spur

$1,781,0,833$ ”

$7,135,3,733$ "

$5,414,4,474$,

12,093 " 8,684 "

15,832 " 25,970 ,

Summa: 99,599 . 99,806 . 
2) Herniaria glabra.

$\begin{array}{cc}\text { Von Kiesel- } & \text { bo } \\ \text { boden. } & \begin{array}{c}\text { Von Dolomit- } \\ \text { boden. }\end{array}\end{array}$

Ausbeute der lufttrocknen Pflanzen

an Asche

$$
\text { 7,132 Proc. 6,622 Proc. }
$$

Procentische Zusammensetzung der Aschen.

\begin{tabular}{|c|c|c|c|c|}
\hline Kali & $24,380 \mathrm{P}$ & roc. & $8,680 \mathrm{H}$ & Proc. \\
\hline Natron & 4,110 & , & 3,860 & 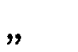 \\
\hline Natrium (mit dem Chlor rerbunden) & 1,702 & " & 0,691 & 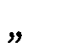 \\
\hline Kalk & 14,349 & $"$ & 30,400 & $"$ \\
\hline Magnesia & 6,300 & " & 14,839 & 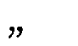 \\
\hline Alaunerde & 1,321 & $"$ & 1,755 & $"$ \\
\hline Eisenoxyd & 1,038 & $"$ & 0,430 & " \\
\hline Manganoxyduloxyd & - & & - & \\
\hline Chlor & 2,624 & ” & 1,066 & , \\
\hline Schwefelsäure & 1,717 & $"$ & 1,746 & $"$ \\
\hline Phosphorsäure & 9,729 & " & 8,421 & , \\
\hline Kieselsäure & 14,445 & $"$ & 6,367 & $"$ \\
\hline Kohlensäure & 17,694 & $"$ & 21,505 & $"$ \\
\hline $\mathrm{ur}_{0}$ & $99,409$. & & 99,760 . & \\
\hline
\end{tabular}

\section{Mittel zur Erkennung der Mineralsäuren im Essig.}

\section{Yon Strobl.}

Dieses Mittel gründet sich auf die Unlöslichkeit des oxalsauren Kalks in verdünnter Essigsäure und dessen Löslichkeit in verdünnten Mlineralsäuren. Das hier zu verwendende Reagens ist daher der oxalsaure Kalk. Da die Reagentien um so empfindlicher, je frischer sie sind, so muss man dahin trachten, den oxalsauren Kalk erst in dem Augenblicke zu erzeugen, wo er wirken soll, indem man nemlich in die zu untersuchende Flüssigkeit bestimmte Mengen aufgelösten oxalsauren Ammoniaks und Chlorcalciums giesst. Da sie aber um so sauerer sein muss, je mehr oxalsaurer Kalk aufzủlösen 